\title{
La fiducia de parqueo inmobiliario como un instrumento de planeación tributaria*
}

\section{The real estate park trust as an instrument of tax planning}

\section{Miguel GUillermo OBREgón URREgo ${ }^{1}$}

\section{Resumen}

El análisis estadístico emitido por boletines como los de la "Asociación Fiduciarias de Colombia"2 muestra un aumento en la utilización dentro del mercado colombiano de la fiducia mercantil y sus variantes, pues se presentan como una excelente herramienta que, desde la planeación estratégica, llevan a una planeación tributaria orientando el manejo de los recursos sin arriesgar el activo líquido que requiere la organización para su curso corriente. Este vertiginoso ascenso se evidencia aún más cuando se extrapola con las reformas tributarias que ha sufrido Colombia en el periodo comprendido por los últimos 15 años, periodo en el cual las empresas han tenido que buscar formas innovadoras de financiarse sin incrementar sus ganancias a niveles tales que la carga tribu- taria las obligue a desistir del negocio que manejan, el cual es la obtención de considerables rendimientos por vía del desarrollo y negociación de bienes inmobiliarios, lo que se encuentra en su objeto social y del cual se derivan todas sus obligaciones fiscales, pero si se logra el justo equilibrio entre el patrimonio, el cubrimiento de obligaciones, sin disminuir el activo social, logrando mantener en el interregno la solidez empresarial, la cual es vital de cara a una clientela que ve en la solidez y cumplimiento el factor determinante para asumir el riesgo en determinado proyecto, todo apunta a un procedimiento altamente técnico y sofisticado donde la garantía de éxito reside en dedicar esfuerzos al cumplimiento del objeto social, en este caso construcción, separado de la comercialización y administración, pero a la vez fijando un mandato claro para así conseguirlo, sien-

* DOI: https://doi.org/10.18601/16926722.n10.07

${ }^{1}$ Contador Público, Universidad Libre. Especialista en Gestión Tributaria, Pontificia Universidad Javeriana. Especialista en Contraloría Financiera, Universidad Javeriana. Magister en Derecho con énfasis en Tributación, Universidad Externado. Magíster en Administración de Empresas -MBA-, Pontificia Universidad Javeriana. Miembro activo del Instituto Colombiano de Derecho Tributario -ICDT-. Miembro activo del Centro de Estudios Tributarios de Antioquia-CETA-; docente activo de la Universidad Libre; asesor Financiero y Tributario de diferentes compañías y Entidades Territoriales; miembro activo de Junta Directiva de Compañía del Sector Privado; revisor Fiscal de Compañía del Sector Privado. Correo electrónico: mgobregon@cgiconsultores.com.co ${ }^{2}$ Asociación de Fiduciarias de Colombia -ASOFIDUCIARIAS- (2015). La Fiducia Inmobiliaria en Colombia. Informe Anual 2015. Bogotá. 
do la fiducia de parqueo la herramienta que brinda todas estas garantías.

Se aclara si la utilidad que se obtiene por la cesión de los derechos fiduciarios y la obtenida por el adquirente de estos derechos se consideran exentas del impuesto de renta, lo cual abriría el espacio para utilizar los beneficios fiduciarios o de derechos fiduciarios para poner bienes, especialmente ganancias fuera del deber de declararlos.

La fiducia de parqueo es una herramienta apropiada para brindar a los propietarios de bienes inmuebles que por objeto social no tienen el desarrollo de estos, de un panorama en el cual puedan poner dichos bienes a nombre de un patrimonio autónomo que se encargara de velar por el cabal cumplimiento de las obligaciones del propio patrimonio, sin que el legítimo propietario afecte negativamente su garantía, frente a terceros, en tanto se cumple la condición plasmada en la fiducia, logrando además que se dé desarrollo a un proyecto que genera enormes movimientos de capital, con sus consabidas ganancias, y al mismo tiempo obteniendo un espacio para no recibir de manera imprevista flujos de efectivo que obligaría al pago de una ganancia ocasional para la cual no se está preparado y que indiscutiblemente afectará la utilidad de ejercicio. Se abre para el usuario de la fiducia, o fiduciante, en aras de proteger su patrimonio de una mala administración y de sus evidentes fallos tributarios en tanto que da fruto su patrimonio, pues encuentra el mejor momento para recibir sus ganancias en virtud de estas pagar la adecuada contribución.

Palabras clave: fiducia mercantil, fiducia de parqueo inmobiliario, planeación tributaria, negocio fiduciario.

\section{Abstract}

Having reviewed the statistics of the increase in the use of mercantile trust in the Colombian market, it is observed that it is an effective formulation of strategic planning in the financial area of companies that use this method. This vertiginous rise is marked when it is extrapolated with the tax reforms that Colombia has undergone in the same period. It clarifies whether the income obtained by the assignment of fiduciary rights and that obtained by the acquirer of these rights are considered exempt from income tax, which would open the space for the use of fiduciary or fiduciary rights to place goods, Especially profits out of the duty to declare them.

Key words: the mercantil trust, the fiducia of real estate, tax planning, fiduciary business.

\section{Sumario}

Introducción. I. La fiducia de parqueo como instrumento de planeación tributaria en los negocios inmobiliarios. A. Análisis del modelo de fiducia de parqueo. B. problemática de la aplicación tributaria en esos negocios de fiducia. II. Aplicación de herramienta de planeación tributaria bajo la figura de la fiducia de parqueo. Conclusiones. Referencias.

\section{Tabla de abreviaturas}

NIT Número de Identificación Tributaria

ET Estatuto Tributario

DIAN Dirección de Impuestos y Aduanas Nacionales 


\section{Introducción}

La consulta surge porque en ejercicios tributarios se puede ver el efecto que disminuye el pago, cuando resulta diferente el tratamiento dado por la venta del inmueble con fines de utilidad pública que la enajenación de los derechos fiduciarios por parte del respectivo patrimonio autónomo, pues se evita el pago por ganancia ocasional, condición que es atribuible a la renta exenta y no a la renta líquida del ejercicio.

Con el ánimo de resolver este cuestionamiento se dará un desarrollo de la clara explicación de la figura de la fiducia de parqueo, los diferentes conceptos expresados por la DIAN en el manejo de las cargas tributarias que realizan los contribuyentes que se acogen a la figura.

Según el parágrafo del artículo $1 .^{\circ}$ del Decreto 2049 de 2006, en el que expresamente se indica que: "El negocio fiduciario no podrá servir de instrumento para realizar actos o contratos que no pueda celebrar directamente el fideicomitente de acuerdo con las disposiciones legales".

El contrato de "fiducia de parqueo" no tiene unas normas especiales, puesto que esta regentada por estas de la fiducia mercantil, y la naturaleza conexa de las cláusulas que las partes expresan en su constitución en desarrollo del principio de la autonomía de la voluntad de estas, como tampoco existe restricción a las partes del contrato a determinar en el acto constitutivo el número de personas en calidad de fideicomitentes, con lo cual el establecimiento del alcance de sus derechos y obligaciones, así como las condiciones de su participación en el proyecto quedan fija- das solo por el cumplimiento transparente de la norma general.

\section{La fiducia de parqueo como instrumento de planeación tributaria en los negocios inmobiliarios}

Como explica la Superintendencia Financiera de Colombia, Concepto 2012043756-001, 2 de agosto de 2012:

La denominada fiducia de parqueo se caracteriza por establecer dentro de su objeto que la sociedad fiduciaria detente la titularidad del inmueble, en su condición de titular y como vocera del patrimonio autónomo, hasta el cumplimiento de las condiciones establecidas en el acto constitutivo o de las instrucciones que imparta el fideicomitente ${ }^{3}$.

Esta denominación, fiducia de parqueo, se encarga de involucrar a las personas interesadas en desarrollar un predio, haciendo uso de la construcción y posterior comercialización de los inmuebles resultantes, pero dando plena libertad para que los participantes asuman o no ciertas responsabilidades en la titularidad del inmueble originario y, así mismo, de los resultantes, hasta que se cumpla la condición con la que se constituyó el patrimonio autónomo, lapso de tiempo en el que los fiduciantes, o quienes originaron el patrimonio autónomo, aseguran la garantía, por fuera de su administración y, por ende, del manejo de las cargas fiscales, para dedicarse de esta manera a trabajar en lo que conocen, que es precisamente el desarrollo del inmueble, la comercialización de este,

${ }^{3}$ Superintendencia Financiera de Colombia, Concepto 2012043756-001, 2 de agosto de 2012.

Revista de Derecho Fiscal n. ${ }^{\circ} 10$ • enero-junio de 2017 • pp. 103-16 
sin tener que preocuparse por movimientos financieros y tributarios que los harían entrar en desgaste, llevándolos inclusive a tomar malas sediciones en virtud de tener que atender temas en los que no son expertos.

El contrato de "fiducia de parqueo" no lleva a un marco normativo especial diferente del que rige a la fiducia mercantil, y el carácter vinculante de las estipulaciones que las partes plasman en el acto constitutivo en desarrollo del principio de la autonomía de la voluntad de estas, como tampoco existe restricción a las partes del contrato a determinar en el acto constitutivo el número de personas en calidad de fideicomitentes, con lo cual el establecimiento del alcance de sus derechos y obligaciones, así como las condiciones de su participación en el proyecto quedan fijadas solo por el cumplimiento transparente de la norma general.

Actualmente la fiducia de parqueo es una de las aplicaciones de la fiducia de administración más importante en el país, puesto que su objeto de negocio recae sobre inmuebles como lotes, casas, urbanizaciones o proyectos de construcción, y como explica Rengifo: "permite acometer actividades que se extienden desde la simple administración de inmuebles hasta el desarrollo de grandes proyectos de construcción, pero se han concentrado la mayoría de sus operaciones en el negocio de la construcción sobre planos"4, lo que posibilita que la fiducia se dé sobre un lote de terreno al cual se le da destinación para viviendas de interés social, o centros comerciales, clubes sociales, oficinas, etc., pero los derechos fiduciarios tendrán el costo fiscal y las condiciones tributarias de los bienes o derechos aportados al patrimonio autónomo, lo que la reforma tributaria del año 2012 hace, es llevar estos valores a tener que ser declarados provocando una avalancha de nuevos movimientos para que las empresas puedan utilizar esta figura más como una herramienta de planeación fiscal, que le quita su atractivo como método de evasión.

La fiducia de parqueo es por si sola una herramienta de planeación tributaria pues al separar el patrimonio autónomo de su creador, estableciendo en la fiduciaria toda su vocería y responsabilidad en tanto que la titularidad se mantiene, se tiene el respaldo necesario sin necesidad de castigar el patrimonio, resultando por demás sano que en el proceso se cubran a nombre de este patrimonio sus cargas fiscales, situación que resulta altamente provechosa pues al cumplirse con la legalidad se garantiza que en el momento del reintegro del patrimonio autónomo a su legítimo propietario este estará totalmente en regla.

\section{A. Análisis del modelo de fiducia de parqueo}

En ella intervienen: fideicomitentes 1 . Son los dueños del inmueble-lote que parquean el bien en la fiduciaria. Fideicomitentes 2 . Son los que van a comprar el inmueble-lote que se va a parquear en la fiduciaria. Los beneficiarios 1. Son los dueños del lote, quienes son beneficiarios de los derechos asociados a este. A medida que se van realizando los pagos por los eventuales compradores, igualmente se realiza la sesión de derechos fiduciarios a estos, desgravando el

${ }^{4}$ Rengifo, E. (2012). La fiducia mercantil pública en Colombia. Universidad Externado de Colombia. Tercera edición. Bogotá. 
patrimonio de estos bienes que salen inclusive del patrimonio autónomo para constituirse en patrimonio del nuevo propietario que, a través de su adquisición, cumple con las cargas tributarias frente al Estado. Y 2. Son los compradores, quienes van adquiriendo beneficios en la medida en que van pagando el lote, beneficios como la propia valorización que en un inmueble desenglobado pesara menos que en un gran globo de terreno hasta antes improductivo, pero que gracias al desarrollo generó trabajo para una industria y bienes de comercio para otras empresas asociadas al proceso, como son las administradoras.

En la fiducia de parqueo, al igual que en cualquier esquema fiduciario, es el fideicomitente el que establece las condiciones que se deben cumplir para la disposición de los bienes fideicomitidos. Su finalidad es la de administrar y ser vocera de bienes inmuebles aportados para desarrollo de proyectos inmobiliarios, teniendo por finalidad que el patrimonio autónomo administrado por la fiduciaria sea el titular jurídico del bien que se le transfiere, con el propósito de: (i) modificar el Contrato de Fiducia Mercantil de administración a un fideicomiso inmobiliario, en el evento en que se haya cumplido las condiciones del contrato de preventas y siga el desarrollo del proyecto de construcción; (ii) se efectúe el ajuste fiscal del inmueble 5 . Dentro de estos efectos se promueve que la fiduciaria esté atenta a la verificación que se cumplan las condiciones establecidas por quien constituyó la fiducia manteniendo un estricto control de las obligaciones propias del fiduciante.

\section{B. Problemática de la aplicación tributaria en esos negocios de fiducia}

Dado el desarrollo del sistema financiero colombiano y el constante aumento de los servicios por este ofrecido, aparecen figuras que sin ser novedosas al ser ofertadas en el mercado, obrando de por medio una legislación tributaria que grava fuertemente las ganancias a los empresarios, hace que afloren caminos marcados para obtener los más altos rendimientos con apego al sistema, estableciéndose como una figura de planeación tributaria, o por el contrario se encuentra el camino de menor resistencia para descargar gruesos capitales a la hora de presentarse ante una declaración tributaria, lo que da paso a una maniobra de evasión fiscal con respecto al impuesto de renta, que ataca directamente a la renta gravable, descargando de ella la mayor cantidad posible de activos, al ponerlos momentáneamente en otro patrimonio, lo que genera un espacio en procura de tiempo para salvar las inversiones y de esta forma responder más adelante en el tiempo por los dineros de los tributos correspondientes.

Tal es el caso de la fiducia mercantil que al generar un capital autónomo podría utilizarse por lo menos momentáneamente para bajar la base gravable en el impuesto a la renta, que opera según el artículo 127 de la Ley 1607 de 2012, para la determinación del impuesto sobre la renta en los contratos de fiducia mercantil.

Pero así mismo, el artículo 271-1 del Estatuto Tributario consagra las reglas para la determinación del valor patrimonial de

${ }^{5}$ Fiduciaria Bogotá, 2016. 
los derechos fiduciarios, señalando que estos deben ser declarados por quien tenga la explotación económica de los respectivos bienes, y para el caso de haber cedido estos derechos no será la sociedad o persona, natural o jurídica, que le dio vida.

Las utilidades o pérdidas obtenidas en los fideicomisos deberán ser incluidas en las declaraciones de renta de los beneficiarios, en el mismo año gravable en que se causan a favor o en contra del patrimonio autónomo, conservando el carácter de gravables o no gravables, deducibles o no deducibles, y el mismo concepto y condiciones tributarias que tendrán si fueren percibidas directamente por el beneficiario.

De aquí que si lo que se desea es evadir se tomarían las pérdidas y se aplicarían al balance y en caso de existir ganancia se mantendría el patrimonio autónomo, estableciendo que debe ser el que mantiene la explotación económica del fideicomiso quién se encarga de asumir los tributos.

En cuanto a los efectos declarativos por certificación por parte de la fiducia, se entiende que cuando constituyente y beneficiario coinciden, opera la transparencia fiscal y debe entenderse que los bienes se conservan en el patrimonio del mismo contribuyente, pues es claro, que no se pueden aplicar pérdidas para disminuir el patrimonio de quien tiene los derechos tributarios, pero si el propio patrimonio podría estar presentando una disminución de su base gravable, maniobra contable, que daría tiempo para sacar dineros de una declaración de renta y ser restituidos a modo de pago en cuando se cumpla la condición que dio origen a la fiducia y, por ende, el beneficiario deberá responder por el total de los bienes y sus réditos al momento de declarar.

Puesto que se manejan patrimonios que no son propios, el artículo 271-1 del Estatuto Tributario ordena que el "certificado que expide la fiduciaria" debe contener los rendimientos acumulados hasta el 31 de diciembre del respectivo ejercicio, aunque no haya sido liquidados en forma definitiva y los rendimientos del último ejercicio gravable y que, en caso de que las cifras incorporen ajustes por inflación de conformidad con las normas vigentes hasta el año gravable 2006 , se deberán hacer las aclaraciones de rigor.

Por tanto, el beneficiario debe declarar el valor patrimonial de su derecho fiduciario según el patrimonio líquido del fideicomiso, y revisar si en los valores certificados se han incluido rubros que corresponden a valores contables pero que no deben ser tenidos en cuenta para efectos fiscales. En esta forma, el valor patrimonial del bien dado en fideicomiso no debería diferir del valor patrimonial del bien en que se encuentra representado, por tanto queda demostrado que el hecho generador del pago de impuestos no ha tenido acontecimiento toda vez que se encuentra una condición que suspende temporalmente el hecho declarativo, en tanto los bienes regresan al beneficiario y se genera la utilidad que da origen a la tributación, en caso contrario el derecho fiduciario se declara a la espera que se cumpla la condición.

Antes de la reforma de la Ley 1607 de 2012, el negocio fiduciario podía arrojar utilidades o pérdidas, pero para efectos del impuesto sobre la renta tiene relevancia la utilidad, no la pérdida, esto conllevaba que se presente la oportunidad de llevar a pérdida

${ }^{6}$ DIAN, Concepto n. ${ }^{\circ} 20030379721.10$ de octubre de 2003. 
todas las entradas de dinero a una empresa que opere bajo esta figura de fiducia provocando el consabido efecto de disminución en su patrimonio y, por ende, una baja en sus libros contables, lo que se apunta para ser usado como una maniobra en la evasión fiscal. Con respecto a las ganancias, el beneficiario del fideicomiso tenía la obligación de declarar las utilidades de los negocios fiduciarios, no las pérdidas?

En la práctica, el funcionamiento del mecanismo fiduciario con mayor efectividad para los intereses de los partícipes en una determinada operación, en su gran mayoría, consisten en desarrollar grandes proyectos urbanísticos y a la vez obtener las garantías para no arriesgar la inversión, cuando existen vastas extensiones de terreno las cuales están en cabeza de personas naturales, fundaciones, congregaciones religiosas, industriales no desarrolladores que tomando en consideración la normativa urbanística cada vez más compleja, los impuestos a la propiedad, la espiral de precios, los gastos administrativos inherentes y demás factores, impulsándolos a querer convertir en dinero la tierra, a desear participar en la creciente de precios, pero sin riesgos económicos y con el mínimo impacto fiscal, ya que su factibilidad lo obliga a acreditar el "costo real de adquisición" (es el coste efectivo de una operación, que se obtiene añadiendo al precio de compra todos los gastos accesorios que sean necesarios para su puesta en condiciones de funcionamiento, fundándose cómo la base que se grava en toda actividad), siendo este el punto en que la figura de la fiducia de parqueo facilita la programación tributaria, pues extiende el plazo del hecho generador del impuesto al tener la responsabilidad fiscal en cabeza de otro titular de esta obligación, permitiendo que se desarrolle el proyecto, dedicado única y exclusivamente a su adelantamiento, para que en el momento que se cumpla la condición y se presente la transferencia de la titularidad se dé inicio al saneamiento fiscal.

Es de aclarar que, en materia de derecho privado, cuando haya transferencia de la propiedad de los bienes se estará ante la denominada fiducia mercantil regulada en el artículo 1226 y siguientes del Código de Comercio; en caso contrario, se estará ante un encargo fiduciario.

En todo caso este proceso es a largo plazo, pues en el primer año de aplicación de la figura no se verán los beneficios, los cuales necesitan de un término mínimo asociado al propio desarrollo físico del proyecto que es el condicionante de la propia fiducia. Optar por una fiducia de parqueo para generar una transferencia de capitales, comprende valorar en el mediano plazo, la capacidad contable de la persona natural o jurídica que desea asumir esta forma un planeamiento estratégico de su tributación, pues de cometer errores o presentar de forma desordenada la contabilidad a los entes reguladores no les quedará otro camino que presumir la evasión fiscal, pues las practicas utilizadas en este manejo apuntan claramente a posponer el hecho generador, pues aplaza el ingreso, y no suma las utilidades sino hasta el momento en que se tiene la verdadera intención de hacerse responsable por el pago, de la misma forma solo hasta ese momento se reportará el ingreso, sin aplicación de gastos, pues estos habrán sido proyectados por el patrimonio

${ }^{7}$ Estatuto Tributario, artículo 102. 
autónomo y, por tanto, estaríamos ante las puras utilidades de un ejercicio que si bien no se desarrolló de manera directa, sí corresponde a los capitales que directamente invirtió el fiduciante.

\section{Aplicación de herramienta de planeación tributaria bajo la figura de la fiducia de parqueo}

Este proceso resulta extendido en el tiempo y se aplica para dar manejo a grandes sumas de dinero, pues de su seguimiento no se consigue dinero en efectivo, sino el descuento sobre la valorización que consiga un bien inmueble tratado por esta figura.

1. Adquisición del lote. Con total disposición se adquiere un bien inmueble, cuyo valor comercial es apreciable, pero no excede los límites de lo que se podría considerar una exagerada riqueza, de forma tal que se hace la negociación adquiriéndolo a crédito por espacio de dos años en la financiación, dejando a financiar un monto no superior al $50 \%$ del costo de adquisición.

Una vez trascurrido el primer año como propietario del predio, se procede a declararlo por el doble de su avalúo catastral, condición que lo pone en vía de alcanzar su valor comercial, o por lo menos el deseado, sin que en una posterior venta se tenga que exagerar los márgenes por ganancia ocasional, entendiendo en todo momento que la sociedad que realiza estos movimientos tiene como objeto social adelantar este tipo de negociaciones.

Con el respectivo incremento del avalúo catastral, se hace el justo pago de lo que el ejercicio arroje, en tanto se cancela la parte del crédito que se tiene por la compra de dicho lote reportándolo como una salida de capital de la empresa destinado al cumpli- miento de una obligación por la compra de un activo.

$\mathrm{Al}$ correr del segundo año, se hace la cancelación total del predio, desagregando estas partidas en la contabilidad empresarial y procediendo casi que de manera inmediata a entregarlo a una sociedad fiduciaria, cuyo encargo será desarrollar un proyecto de vivienda de estrato elevado, pero esta vez con un lote que figura catastralmente por el doble del valor inicialmente adquirido, lo que conlleva que en un tercer año de vigencia de la actividad se pueda apuntar a las reglas del libre autoevaluó, liberando el valor dado a la tierra y declarándolo por un mayor valor en todo caso más conveniente para efectos de la valorización que ha de presentarse sin tener que salir a responder por la ganancia ocasional, ya que desde el punto de vista de la razón social de la entidad que administra el encargo existe este objeto social que automáticamente lo separa de este tributo, pues se contempla no una ganancia ocasional, sino un efecto positivo del objeto social suscrito.

2. Inicio de obra. Es en este momento cuando se escoge de pasar a realizar las ventas independientes, para declarar desagregadamente un valor por cada unidad vendida y no por el precio total del "globo" de terreno, que para este entonces gravita por sumas astronómicas, que de mantenerse en un patrimonio concreto ya estarían muy por encima de los montos de declaración y pago.

3. Mercadeo y venta del proyecto. Otro adicional que se imbrica en el manejo de estos lotes en parqueo, aparece al momento de establecer que el desarrollo del propio lote ha generado unos gastos que se cubren con las ventas individuales de cada porción de lote desarrollado que se realiza, permitiendo subir el valor del negocio y no del lote en sí mismo. Situación que al ser manejada por 
una sociedad que se encarga de administrar el bien inmueble responde solo por el desarrollo, con sus gastos y utilidades y no por un lote que es el objeto y asiento material del propio negocio, así de esta forma la persona natural o jurídica que aportó el lote a la fiducia a título de parqueo, recibirá el pago del valor originario del lote, aun cuando este se ha valorizado paulatinamente a lo largo de los tres primeros años, o si es del caso de un tiempo mucho más largo, pues aquí en tiempo solo aporta más valor pues al marcar la diferencia entre el precio de adquisición con el precio de venta de las unidades privadas $\mathrm{y}$ al no poder imputar este valor al globo de terreno directamente solo se estaría pagando por la venta, a la cual se le pueden aplicar gastos y costos, que van directamente contra el activo, desinflando una vez más el patrimonio, además de tener que cubrir también los gastos de administración, construcción y las consabidas perdidas que se den.

En el transcurso intermedio se puede hacer manejo de los valores reportados como utilidad al cruzarlos con pérdidas y gastos asociados al desarrollo del lote, que debe estar en cabeza de una sociedad que tiene por objeto social dicho desarrollo, lo puede hacer sin que se presente ningún quebranto a la norma tributaria, o sin presentarlo como prácticas evasivas, pues tanto el hecho generador, como la obligación tributaria se presentan claras para los diferentes participantes de la operación, es decir, aportante del lote (fideicomitente), fiducia, la cual subcontrata al desarrollador (constructor) y comercializador, el cual puede ser exactamente el mismo fideicomitente, quien se encargará de responder por los impuestos correspondientes, por la labor adelantada de construcción y desarrollo, sin que su patrimonio se vea inflado, toda vez que no es- tamos hablando del patrimonio de la misma persona natural o jurídica, sino de encargos de tracto sucesivo, que se liquidan de acuerdo con su cumplimiento.

Las cargas tributarias siempre obedecerán a sus hechos generadores y tarifas propias, por tanto, se cumple en estricto sentido y se puede escoger el momento más apropiado para el pago dentro del desarrollo de cada actividad, sin que el patrimonio se infle o se acumulen cantidades muy evidentes de dinero, inclusive algunos ejercicios pueden arrojar pérdida, situación que no castiga al fisco nacional, pero que si reporta una menor utilidad de la operación.

4. Avalúos de los bienes fideicomitidos. La obligación del fideicomitente de aportar los bienes y de proveer recursos para sufragarlos, los cuales se pactan del propio desarrollo del bien inmueble, pues como capital autónomo tiene que ser autosostenible, pudiendo mostrar en este una gestión de trabajo de su propio capital, el cual para generarse requiere una aplicación de gastos que mantendrá controlado el mayor valor resultante.

Las consecuencias e implicaciones que para las partes, deudores y acreedores del fideicomiso acarrea el incumplimiento de dicha obligación, son asumidas por el fideicomiso que se encarga de administrar el patrimonio, y del cual se puede expresar cifras claras que afectan la valorización del bien inmueble, obligándolo a no disparar su avalúo, pues a futuro se espera que este inmueble no pese mucho en el balance, ya que es fruto de la venta de unidades privadas desarrolladas a partir del encargo fiduciario se tendrán que cubrir todos estos gastos asociados, lo que reduce la utilidad y por tanto presenta un balance más económico de manejar en materia tributaria. 
El alcance de la responsabilidad de la sociedad fiduciaria en la contratación, designación del avaluador y contenido del avalúo, son gastos que se deben cancelar y, por ende, disminuye el valor reportado.

Finalmente, para llegar a la liquidación, del contrato de fiducia, debe establecerse de modo claro el procedimiento y los términos para hacerlo, incluyendo los eventos en los cuales haya necesidad de hacer pagos por conceptos de impuestos, siendo este momento el que se aprovecha para hacer el pago en el mejor momento, es decir, cuando se tenga flujo de efectivo por concepto de ventas realizadas, transfiriendo este valor al comprador inicial y no al fideicomitente que aportó el bien en parqueo, otros valores que deberán pactarse son tasas o contribuciones, pues si bien son responsabilidad de la sociedad fiduciaria estarán gravando al originador del patrimonio autónomo, que debe establecer con claridad cuanto fue lo que ganó producto de esta operación para establecerlo como pago a un ingreso no operacional, por tal motivo la utilidad presentada en este ejercicio debe ser mínima, lo que hace que la ganancia real la asuma en el pago de una actividad que esté dentro del objeto social, como lo es la construcción y desarrollo del lote, lo que explica que el aportante resulta ser por regla general el constructor. Que a diferencia del propietario del lote no posee la capacidad jurídica para asumir una empresa como la construcción, pero que tampoco se verá a abocado a recibir dineros por la vía de la ganancia ocasional.

Con la lectura del artículo 102 de Estatuto Tributario se puede determinar:

Se puede prever la vinculación de terceros interesados en la finalidad del proyecto, por ejemplo, cuando a través del negocio fiduciario se pretende construir un edificio de apartamentos y se vinculan al mismo, como beneficiarios, personas interesadas en adquirir uno o varios apartamentos.

Los beneficiarios de un fideicomiso pueden deducir las pérdidas que registró el patrimonio autónomo. Que la posición de la DIAN es contradictoria, porque

no desconoce que se puedan restar los costos y gastos que se producen dentro de los fideicomisos, sino que escinde los ingresos de los costos y deducciones, determinando que los primeros sean declarados por el beneficiario o fideicomitente y los segundos por la fiduciaria, lo cual no cuenta con respaldo legal alguno.

Se causará el impuesto sobre la renta o ganancia ocasional en cabeza del constituyente, siempre que los bienes que conforman el patrimonio autónomo o los derechos sobre el mismo se transfieran a personas o entidades diferentes del constituyente. Si la transferencia es a título gratuito, el impuesto se causa en cabeza del beneficiario de los respectivos bienes o derechos. Para estos fines se aplicarán las normas generales sobre la determinación de la renta o la ganancia ocasional, así como las relativas a las donaciones y las previstas en los artículos 90 y 90-1 de dicho estatuto.

Modificado por el artículo 82 de la Ley 488 de 1998. En relación con cada uno de los patrimonios autónomos bajo su responsabilidad, los fiduciarios están obligados a cumplir las obligaciones formales señaladas en las normas legales para los contribuyentes, los retenedores y los responsables, según sea el caso. Para tal efecto, se le asignará un NIT diferente al de la sociedad fiduciaria, que identifique en forma global a todos los fideicomisos que administre. 
Las sociedades fiduciarias presentarán una sola declaración por todos los patrimonios autónomos. La sociedad fiduciaria tendrá una desagregación de los factores de la declaración atribuible a cada patrimonio autónomo a disposición de la DIAN para cuando esta lo solicite.

De conformidad con el artículo 26 E.T., dentro del proceso de depuración, después de las rentas brutas se restan las deducciones realizadas con el fin de obtener la renta líquida. Las operaciones o negocios que son regulados, específicamente, en el capítulo IV, libro I del E.T., por su naturaleza o por la normatividad misma que las regula no se oponen a una depuración de la renta que determine incluso la generación de resultados negativos o de pérdida. Que, por el contrario, a voces del artículo 26, a la renta bruta se restan las deducciones realizadas para obtener la renta líquida que es la gravable.

Debe tenerse en cuenta que la Ley 223 de 1995 tuvo como fin regular íntegramente el régimen tributario en la fiducia y que, por tanto, la interpretación sistemática del capítulo I, título I del libro I del E.T. permite concluir que también se deben aplicar las normas de costos y deducciones. Que esa interpretación se deduce de la lectura del artículo 26 del E.T.

El artículo 271-1 del E.T. establece que los derechos sobre el patrimonio autónomo y los costos y gastos relacionados con los bienes afectos a ese patrimonio deben ser declarados por quien los explota económicamente, es decir, por la fiduciaria. Que otra cosa era el valor patrimonial de los derechos fiduciarios que detenta el fideicomitente y beneficiario, que se determina con base en la participación en el fideicomiso.

\section{Conclusiones}

La fiducia de parqueo resulta un instrumento para hacer una adecuada planeación tributaria, pues desagrega de forma ordenada y sin peligro de desvalor de acción, patrimonios que de otro modo tendrían que ser contabilizados como una pérdida o un mal negocio que se presenta por fuera del giro ordinario del objeto social de la empresa que generó dicho patrimonio autónomo. La condición se advierte cuando a la cancelación de la fiducia quien generó el patrimonio ve saneada sus obligaciones fiscales, pues el administrador fiduciario ha cumplido con este deber, y por vía de los beneficiarios puede recuperar el capital inicialmente liberado con sus respectivos rendimientos.

Las utilizaciones de negocios fiduciarios facultan que se puedan llevar ganancias a patrimonios diferentes al del causante, con lo que se puede establecer una disminución de capital sin que esto signifique pérdida o responsabilidad sobre estas utilidades, toda vez que a lo largo de su administración fiduciaria se ha cancelado sus respectivas cargas tributarias, quedando solo en manos de quien los recibe como su beneficiario hacer las cancelaciones respectivas llegado el caso.

No existe evasión fiscal en las figuras de fiducia de parqueo, pues cada responsable comercial se hace responsable fiscal, solo se manejan los tiempos de pago y los montos por los cuales se está dispuesto a pagar, constituyéndose en una forma útil de anticipar el monto de un tributo a muy largo plazo, estimado entre 5 y 20 años, lo que enmarca el desarrollo inmobiliario y la vida legal de una fiducia, pudiendo incluso por vía de los beneficiarios iniciar nuevamente el ciclo consiguiendo los beneficios inicialmente 
planteados, otorgando a los inversionistas el derecho a participar de los resultados económicos derivados del cumplimiento de la finalidad del negocio, sin que implique la propiedad del bien objeto del proyecto, lo que de antemano es una programación en materia tributaria ya que con anticipación se preparan las cargas para ser presentadas y no asumir impuestos por elementos que no están dentro del objeto social de la empresa que acude a este mecanismo o de la persona natural que no puede inflar más allá de los límites naturales su declaración.

Se acogerá al hecho del pago bajo un solo título quien tome la decisión de optar por el negocio fiduciario, esto quiere decir que la ley lo cobijará con la presunción de buena fe de haber reportado un pago y efectivamente haberlo realizado, no deberá pagar dos veces por el mismo asunto, y bajo el entendido que un patrimonio que cumplió con sus obligaciones no arrastrará a su creador para responder por estos mismos dineros.

El responsable fiscal en todo caso es el administrador del patrimonio autónomo, y el hecho generador de la carga tributaria se da sobre los movimientos que tal patrimonio autónomo tenga en el sistema.

Toda vez que el nacimiento del hecho generador de la contribución no se presenta porque existe un encargo que debe ser cumplido, para que posteriormente se pueda proceder al pago de los tributos, lo que se hace es extender el plazo lo más posible, dejándolo consignado en el propio encargo y de esta manera se genera un tiempo en el cual el fiduciante mantiene "suspendido" el hecho generador, provocando los movimientos financieros que sean necesarios para sacar mayor provecho de su dinero.

Para el caso de la fiducia de parqueo se está ante condición suspensiva o resolutoria, generándose la consabida confusión y este espacio en tanto se cumple la condición será el aprovechado para sacar partido en una planeación tributaria.

Los efectos producto de la actividad fiduciaria en materia de planeación tributaria no son inmediatos, estos muestran sus bondades en el mediano y largo plazo, pues los entes fiscalizadores como la DIAN tienen claro que los patrimonios no desaparecen de un momento a otro, por tal razón lo ejecutado en el primer año debe ser objeto de declaración al término de ese ejercicio, ya con manejos posteriores se puede ampliar el plazo para responder fiscalmente por ellos entrando en el plano de la planeación tributaria vía contrato fiduciario.

Toda vez que el nacimiento del hecho generador de la contribución no se presenta porque existe un encargo que debe ser cumplido, para que posteriormente se pueda proceder al pago de los tributos, lo que se hace es extender el plazo lo más posible, dejándolo consignado en el propio encargo $\mathrm{y}$ de esta manera se genera un tiempo en el cual el fiduciante mantiene "suspendido" el hecho generador, provocando los movimientos financieros que sean necesarios para sacar mayor provecho de su dinero.

Para los fines del impuesto sobre la renta y complementarios, los ingresos originados en los contratos de fiducia mercantil se causan en el momento en que se produce un incremento en el patrimonio del fideicomiso, o un incremento en el patrimonio del cedente, cuando se trate de cesiones de derechos sobre dichos contratos. Es así que terminando cada ejercicio gravable se debe efectuar una liquidación de los resultados obtenidos en el respectivo periodo por el fideicomiso y por cada beneficiario, siguiendo las normas que señala el capítulo I del título I del Estatuto 
Tributario para los contribuyentes que llevan contabilidad por el sistema de causación.

Toda vez que el negocio fiduciario representa un pacto que aporta un bien para la realización de un fin determinado, no puede este objeto desconfigurar la realidad tributaria, estableciendo un campo en el que el responsable no mute a pesar de las transferencias de que pueda ser objeto el bien transferido, o los manejos que realice el patrimonio autónomo que pasa a constituirse con fundamento en los bienes entregados a él.

El Estatuto Tributario busca reflejar el principio de la transparencia en el valor patrimonial de los activos. Es decir, reflejar la realidad económica de los activos entregados en fideicomiso.

Para efectos contables, según el PUC para comerciantes (Decreto 2650 de 1993 modificado por el Decreto 2116 de 1996), la transferencia de bienes en fiducia, debe efectuarse por su costo ajustado de suerte que la entrega en sí misma no genera la realización de utilidades y solo tienen incidencia en los resultados cuando realmente se enajenen a terceros el bien o bienes objeto del fideicomiso.

(El valor asignado al bien o grupo de bienes en fideicomiso se revelará en cuentas de orden bajo el código 839520 - Bienes y Valores en Fideicomiso). La misma ley contable se ha encargado de establecer las cuentas en que deben registrarse los contratos fiduciarios, tal como puede verse en el Decreto 2649 de 1993.

Si del contenido del contrato puede establecerse que existe transferencia de bienes a una persona distinta del constituyente, bien en el acto de constitución o durante el desarrollo de la fiducia mercantil, por cuanto quien ostenta la explotación económica del bien fideicomitido es una persona diferente al constituyente, los efectos tributarios que en materia patrimonial se predican, son los siguientes:

a. Existe una verdadera enajenación con todas las consecuencias que señalan los artículos 90 y siguientes del Estatuto Tributario.

b. Los activos salen del patrimonio del fideicomitente y este no debe registrar derechos fiduciarios en su patrimonio, por cuanto los bienes han sido enajenados y es al beneficiario, a quien le corresponde registrar los derechos fiduciarios originados en el contrato de fiducia mercantil. Lo anterior por cuanto el artículo 271-1 dispone que los derechos sobre el patrimonio deben ser declarados por el contribuyente que tenga la explotación económica de los respectivos bienes, en armonía con lo dispuesto en el artículo 263 del mismo ordenamiento. 


\section{Referencias}

Fiduciaria Bogotá. Transparencia en el manejo de sus recursos. Bogotá, 2016. Recuperado de Bogota.com/wps/ themes/html/fidubogota/inmobiliaria-fiducia-mercantil-administracion-parqueo.html.

Rengifo, E. (2012). La fiducia mercantil pública en Colombia (3. ${ }^{a}$ ed.). Bogotá: Universidad Externado de Colombia.

Ley 1607 de 2012. Artículo 127.

Estatuto Tributario. Artículo 102.

Superintendencia Financiera de Colombia, Concepto 2012043756-001, 2 de agosto de 2012. Concepto n. ${ }^{\circ}$ 20030379721, 10 de octubre de 2003. 